\title{
Conforto térmico de vacas leiteiras mestiças durante a inseminação e a relação com a taxa de concepção
}

\section{Thermal comfort of crossbred dairy cow during insemination and the relation with the conception rate}

\author{
Henrique Barbosa Hooper ${ }^{1 *}$, Daniela de Oliveira Santana Salomão², Gustavo Ferreira Ayres², Cristiane Gonçalves \\ Titto $^{1}$, Ricarda Maria dos Santos², Mara Regina Bueno de Mattos Nascimento² \\ ${ }^{1}$ Universidade de São Paulo (USP), Pirassununga, SP, Brasil \\ 2 Universidade Federal de Uberlândia (UFU), Uberlândia, MG, Brasil
}

\section{Resumo}

Avaliou-se o conforto térmico de vacas leiteiras mestiças, anteriormente à inseminação artificial, e a relação com a taxa de concepção. Este estudo foi realizado em Uberlândia, Minas Gerais, região caracterizada por invernos secos e verões chuvosos, utilizando 112 vacas leiteiras mestiças, cuja composição genética envolvia as raças Holandesa, Gir, Jersey e Pardo Suíça. Os parâmetros fisiológicos, frequência respiratória e temperatura retal foram mensurados previamente à inseminação artificial, juntamente com os parâmetros ambientais, temperatura, umidade do ar e velocidade do vento. A temperatura mínima e a umidade relativa foram maiores no verão do que no inverno. Já a amplitude térmica foi menor no verão em relação ao inverno $(\mathrm{p}<0,05)$. As temperaturas média e máxima do ar, ITU (índice de temperatura e umidade) e ITE (índice de temperatura equivalente) não diferiram entre as estações ( $p>0,05)$. Observou-se uma tendência de maior taxa de concepção quando as inseminações foram realizadas no ITU $\leq 72(p=0,06)$. Conclui-se que o momento em que foram realizadas as inseminações artificiais contribuiu para que os animais estivessem em conforto térmico e, portanto, não foi observado prejuízo na taxa de concepção das vacas leiteiras mestiças.

Palavras-chave: Bovinos leiteiros. IATF. ITU. ITE. Temperatura retal.

\begin{abstract}
The thermal comfort of crossbred dairy cows prior to artificial insemination and the relation with the conception rate were evaluated. This study was carried out in Uberlândia, Minas Gerais, Brazil, characterized by a dry winter and a rainy summer, in which was used 112 crossbred dairy cows, whose genetic composition involved the Holstein, Gir, Jersey and Brown Swiss breeds. The physiological parameters, respiratory rate and rectal temperature were measured prior to artificial insemination as well as the environmental parameters, air temperature, humidity, and wind speed. The minimum temperature and the relative humidity were higher in
\end{abstract}


the summer than in the winter. The thermal amplitude was lower in the summer compared to the winter $(p<$ 0.05). The mean and maximum air temperatures, THI (temperature and humidity index) and ETI (equivalent temperature index) did not differ within seasons ( $p>0.05)$. $A$ tendency of higher conception rate when inseminations were performed in the THI $\leq 72(p=0.06)$ was noticed. It was concluded that the time when artificial inseminations were executed had contributed to the thermal comfort of animals and therefore was not observed prejudices in the conception rate of crossbred dairy cows.

Keywords: Dairy cattle. AIFT. THI. ETI. Rectal temperature.

\section{Introdução}

O bem-estar e a eficiência reprodutiva de bovinos leiteiros criados em regiões de clima tropical e subtropical são afetados por condições em que a temperatura e a umidade são elevadas e a radiação solar é intensa na maior parte do ano (Silanikove, 2000; Kamal et al. 2018). Nos sistemas leiteiros, a produtividade e lucratividade estão diretamente relacionadas à correta execução de manejos sanitários, nutricionais e reprodutivos, que priorizem a boa relação entre os animais e funcionários, o bem-estar e o conforto-térmico. Sabe-se que os animais estão sob conforto térmico quando não há necessidade de mobilizar mecanismos termorreguladores para se ajustarem às imposições do ambiente (Bernabucci et al., 2010; Van Iaer et al., 2014).

$\mathrm{Na}$ análise do conforto térmico, dois parâmetros fisiológicos de termorregulação são mais utilizados para entender as respostas biológicas em situações de estresse térmico, sendo elas a temperatura retal e a frequência respiratória (Brown-Brandl et al., 2003). 0 ciclo diário da temperatura retal é alterado conforme o metabolismo energético e de água, e está relacionado com a capacidade adaptativa do animal (Finch, 1986; Golher et al., 2015). As mudanças na temperatura corporal promovem alterações nas funções neuroendócrinas e celulares, podendo reduzir crescimento, lactação e fertilidade (Finch, 1986).

Os protocolos de sincronização de estro, a inseminação artificial em tempo fixo (IATF) e o diagnóstico precoce de gestação são alguns dos métodos que contribuem para o bom desempenho reprodutivo do rebanho por reduzirem o intervalo de partos, proporcionarem o estabelecimento rápido da gestação, equilibrarem a produção leiteira e gerarem bezerras para reposição (Barbosa et al., 2011; Smith et al. 2013). A inseminação artificial auxilia no melhoramento genético, no controle zootécnico e de doenças, na prevenção de acidentes e na melhor utilização de touros.

Essas práticas reprodutivas devem ser associadas a medidas que reduzam o efeito do estresse por calor, principalmente em regiões com elevado desafio térmico. As imposições meteorológicas fazem com que os animais saiam do seu estado de equilíbrio térmico, necessitando, assim, desviar energia para aumentar a dissipação ou ganho de calor (Habeeb et al., 2018). Em estresse por calor, os bovinos diminuem o consumo de matéria seca, elevam o consumo de água, aumentam o gasto energético de mantença, mudam o comportamento alimentar e perdem potássio e sódio por sudação e urina, além de ocorrer queda no pH ruminal (Silva, 2000).

Das modificações relacionadas à reprodução de vacas Holandesas, encontra-se a redução dos níveis séricos de estrógeno, do grau de dominância folicular e manifestação do estro, redução da atividade folicular, da qualidade oocitária e do embrião, além de modificações do ambiente uterino que dificultam a implantação do embrião (De Rensis e Scaramuzzi, 2003; Chang et al. 2017). Beltran e Vasconcelos (2008) e Soydan et al. (2009) observaram em vacas Holandesa e Jersey a diminuição da eficiência reprodutiva em determinadas épocas do ano, de acordo com a localidade e sistema de manejo, sendo que a taxa de concepção diminuiu nos períodos mais quentes até mesmo em vacas aclimatadas ao calor.

0 cruzamento de raças que detenham características desejáveis para produção de leite e tolerância ao calor é uma combinação que minimiza os efeitos do estresse térmico, como é o caso do cruzamento entre as raças Holandesa e Gir (Azevedo et al., 2005; Sørensen et al., 2008). Por outro lado, ainda pouco se conhece sobre as respostas termorregulatórias dos animais mestiços em condições tropicais. Portanto, para que medidas possam ser tomadas com a finalidade de favorecer 
a manutenção do conforto térmico, dos índices produtivos e reprodutivos, é necessário conhecer como as variações do microclima local ao longo do ano influenciam as respostas intrínsecas dos animais. Diante do exposto, objetivou-se avaliar o conforto térmico de vacas leiteiras mestiças no momento da inseminação artificial e entender a relação com a taxa de concepção.

\section{Material e métodos}

O presente estudo obteve aprovação para execução (número de protocolo 060/10) pela Comissão de Ética no Uso de Animais da Universidade Federal de Uberlândia (CEUA/UFU), Uberlândia, Minas Gerais. 0 estudo foi conduzido na Fazenda Experimental do Glória da Universidade Federal de Uberlândia, mesorregião do Triângulo Mineiro, município de Uberlândia (Latitude 18 ${ }^{\circ} 3^{\prime} 23^{\prime \prime}$ S, Longitude $48^{\circ} 17^{\prime} 19^{\prime \prime}$ W e Altitude de 865 metros), sendo o clima da região do tipo Aw conforme a classificação de Köppen, com invernos secos e verões chuvosos.

As coletas foram realizadas ao longo de dois anos consecutivos e considerou-se duas estações do ano: o inverno (de abril a setembro) e o verão (de outubro a março). Utilizou-se 112 vacas leiteiras mestiças, saudáveis, sendo 62 multíparas e 50 primíparas. Os animais foram considerados mestiços, pois em sua composição genética envolvia diferentes grupos raciais, dentre elas as raças Holandesa, Gir, Jersey e Pardo Suíça.

As vacas eram ordenhadas duas vezes ao dia. A média de produção de leite era de 19,3 L.dia $^{-1}$. Elas foram mantidas a pasto, gênero Urochloa syn. Brachiaria, e durante o período seco receberam suplementação com silagem de milho. A suplementação concentrada foi administrada diariamente durante as ordenhas conforme a produção leiteira. A água e suplemento mineral foram disponibilizados ad libitum, respectivamente, em bebedouros e cochos localizados nos currais de entrada e saída da ordenha e nos piquetes. 0 calendário sanitário foi seguido regularmente para todo rebanho da fazenda, obedecendo à legislação estadual vigente para bovinos.

O manejo reprodutivo das multíparas foi realizado por protocolo de inseminação artificial em tempo fixo (IATF) com média de $40 \pm 5$ dias pósparto. 0 protocolo de IATF (Figura1) compreendeu, no dia zero, a aplicação intramuscular de $2 \mathrm{mg}$ de benzoato de estradiol (Sincrodiol ${ }^{\circledR}$, Ourofino) mais a inserção do dispositivo intravaginal de progesterona (Sindrogest ${ }^{\circledast}$, Ourofino). No dia 7, administração intramuscular de $12,5 \mathrm{mg}$ de dinoprost trometamina (Lutalyse ${ }^{\circledR}$, Pfizer). No dia 9, retirada do dispositivo intravaginal de progesterona mais aplicação intramuscular de $1 \mathrm{mg}$ de ciprionato de estradiol (E.C.P. ${ }^{\circledR}$, Zoetis), com observação do estro em sequência. 0 protocolo terminou no dia 11, momento final das inseminações.

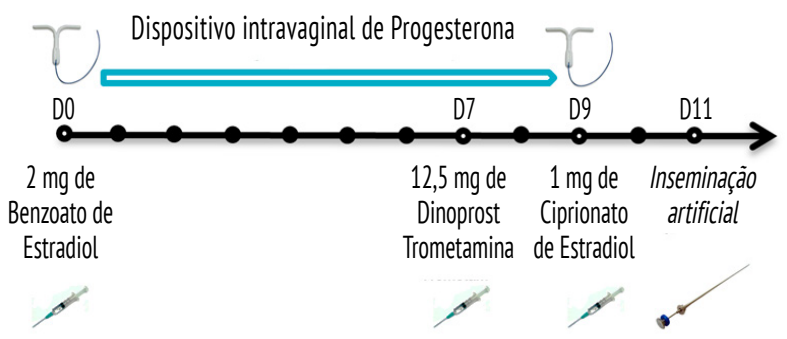

Figura 1 - Diagrama do protocolo de inseminação artificial em tempo fixo (IATF), com a representação dos fármacos e dias de aplicação.

O dispositivo intravaginal de progesterona foi utilizado três vezes. Nas primíparas, foi realizada após detecção visual do estro natural ou, em algumas houve indução do estro pela utilização de prostaglandina. Para confirmação da concepção foi realizado o diagnóstico de gestação por ultrassonografia transretal aproximadamente 28 dias após a inseminação. A taxa de concepção foi calculada pela razão do número de vacas gestantes sobre o número de vacas em serviço, multiplicando o valor obtido por 100 .

O conforto térmico foi mensurado antes da inseminação artificial, por meio de coletas nos animais e no ambiente. Para as avaliações das variáveis fisiológicas, mensurou-se a temperatura retal e frequência respiratória. A temperatura retal foi coletada com termômetro clínico digital (Incoterm ${ }^{\circledR}$, precisão de $\pm 0,2{ }^{\circ} \mathrm{C}$, tempo de aferição de 15 segundos), posicionado em contato com a mucosa retal. A frequência respiratória por 
minuto foi obtida por meio da observação visual dos movimentos respiratórios no flanco direito. Para as avaliações do microclima, coletaramse os parâmetros ambientais, temperatura e umidade do ar, e velocidade do vento. Os instrumentos meteorológicos foram instalados na sala de ordenha, próximo ao local onde foram realizadas as inseminações. As temperaturas de bulbo seco e úmido foram medidas por meio de termohigrômetro (Incoterm ${ }^{\circledR}$, precisão: $\pm 1{ }^{\circ} \mathrm{C}$ ); as temperaturas máxima e mínima, por meio do termômetro de máxima e mínima (Incoterm ${ }^{\circledR}$, precisão: $\pm 1{ }^{\circ} \mathrm{C}$ ), ambos colocados 24 horas antes das coletas. A velocidade do vento foi obtida pelo anemômetro digital portátil (Instrutherm ${ }^{\circledR}$, modelo AD-250, precisão: $\pm 3 \%$ fundo de escala). A amplitude térmica foi calculada pela diferença entre a temperatura máxima e mínima do ar registradas 24 horas antes das coletas em cada estação do ano.

Posteriormente, para melhor compreender o efeito do ambiente térmico, foram calculados o índice de temperatura e umidade (ITU) e o índice de temperatura equivalente (ITE). Para o ITU, seguiuse a equação proposta por Thom (1958): ITU = Ta $+0,36^{*}$ Tpo $+41,5$, em que Ta é a temperatura do ar e Tpo é temperatura de ponto de orvalho, ambas em ${ }^{\circ} \mathrm{C}$. 0 ITE foi calculado de acordo com Baeta et al. (1987 apud Silva, 2000), seguindo a equação: ITE $=27,88-0,456{ }^{*} \mathrm{Ta}+0,010754^{*} \mathrm{Ta}^{2}-$ $0,4905^{*} \mathrm{UR}+0,00088^{*} \mathrm{UR}^{2}+1,1507^{*} \mathrm{~V}-0,126447^{*} \mathrm{~V}^{2}$ $+0,0198776^{*} \mathrm{UR}^{*} \mathrm{Ta}-0,046313^{*} \mathrm{~V}^{*} \mathrm{Ta}$, em que Ta refere-se à temperatura do ar $\left({ }^{\circ} \mathrm{C}\right)$, UR à umidade relativa (\%) e V à velocidade do vento $\left(\mathrm{m} . \mathrm{s}^{-1}\right)$. A taxa de concepção ainda foi relacionada às categorias de ITU ( ITU $\leq 72$ e ITU $>72$ ) e ITE (ITE $\leq 27$ e ITE $>27$ ), com a finalidade de melhor compreender o efeito destes índices com a reprodução.

\section{Análise estatística}

As temperaturas do ar, máxima e mínima, amplitude térmica, umidade relativa, ITU, ITE, temperatura retal e frequência respiratória foram utilizadas como variáveis dependentes, e a estação do ano como independente. Para análise da variância foi utilizado o teste $\mathrm{F}$ e as médias foram comparadas pelo teste de Tukey, pelo modelo linear generalizado (GLMs). Os testes foram realizados a $5 \%$ de probabilidade e os valores apresentados pelas médias e erro padrão da média. Foram estimados coeficientes de correlação simples de Pearson entre os parâmetros fisiológicos e meteorológicos, considerando correlação forte para valores maiores que 0,7 , moderada entre 0,3 e 0,7 e fraca para valores menores que 0,3. Das correlações significativas entre temperatura retal com a temperatura do ar, ITU e ITE, e entre a frequência respiratória com a umidade relativa foram estimadas regressões lineares simples, a 5\% de significância. Para analisar a taxa de concepção foi utilizado o teste Qui-quadrado. Adotou-se um nível de significância de 5\%, em que a taxa de concepção foi associada às estações do ano e aos níveis de ITU e ITE. Todas as análises estatísticas foram realizadas utilizando o software Minitab $^{\circledR}$ 18.1 (Minitab Inc., PA, USA).

\section{Resultados}

As temperaturas média $(\mathrm{p}=0,19)$ e máxima do ar $(p=1,19)$, ITU $(p=0,33)$ e ITE $(p=0,89)$ não diferiram entre as estações do ano. Já a temperatura mínima $(p=0,001)$ e umidade relativa $(p=0,001)$ foram maiores no verão em comparação ao inverno, e a amplitude térmica $(p=0,001)$ foi menor no verão do que no inverno (Tabela 1 ). A temperatura retal $(\mathrm{p}=0,06)$ e a frequência respiratória $(\mathrm{p}=$ $0,40)$ dos animais não diferiram entre o verão e inverno. Houve uma tendência da temperatura retal ser $0,27{ }^{\circ} \mathrm{C}$ maior no verão em relação ao inverno. As correlações entre temperatura retal com a temperatura do ar, com o ITU e com o ITE foram significativas, positivas e moderadas (Tabela 2).

Pelas equações de regressão, estimou-se que a elevação de $0,06{ }^{\circ} \mathrm{C}$ na temperatura do $\operatorname{ar}(\mathrm{p}=0,001)$ (Figura 2), 0,05 unidades no ITU ( $p=0,001$ ) (Figura 3) e $0,03{ }^{\circ} \mathrm{C}$ no ITE $(p=0,001)$ (Figura 4 ) promoveriam o aumento de $1{ }^{\circ} \mathrm{C}$ na temperatura retal.

Observou-se uma tendência de taxa de concepção mais elevada quando as inseminações foram realizadas quando o ITU foi $\leq 72$, e menor no ITU $\geq 72$ (Tabela 3). A taxa de concepção não foi influenciada nem pela estação do ano nem pela categorização do ITE. 
Tabela 1 - Média e erro padrão da média (EPM) para temperatura do ar (Ta), temperatura máxima (Tmax), temperatura mínima (Tmin), amplitude térmica (At), umidade relativa (UR), índice de temperatura e umidade (ITU), índice de temperatura equivalente (ITE), temperatura retal (TR) e frequência respiratória (FR) de vacas leiteiras mestiças no inverno e verão na mesorregião do Triângulo Mineiro

\begin{tabular}{|c|c|c|c|c|c|}
\hline \multirow[b]{2}{*}{ Parâmetros } & \multicolumn{2}{|c|}{ Inverno } & \multicolumn{2}{|c|}{ Verão } & \multirow[b]{2}{*}{$P$-valor } \\
\hline & Média & EPM & Média & EPM & \\
\hline Ta $\left({ }^{\circ} \mathrm{C}\right)$ & 23,84 & 0,36 & 23,16 & 0,46 & 0,193 \\
\hline $\operatorname{Tmax}\left({ }^{\circ} \mathrm{C}\right)$ & 29,19 & 0,19 & 29,74 & 0,75 & 1,191 \\
\hline $\operatorname{Tmin}\left({ }^{\circ} \mathrm{C}\right)$ & 16,29 & 0,33 & 20,88 & 0,47 & 0,001 \\
\hline At $\left({ }^{\circ} \mathrm{C}\right)$ & 12,89 & 0,42 & 8,86 & 0,70 & 0,001 \\
\hline UR (\%) & 82,85 & 0,89 & 94,54 & 1,04 & 0,001 \\
\hline ITU & 71,70 & 0,39 & 73,05 & 0,61 & 0,333 \\
\hline $\operatorname{ITE}\left({ }^{\circ} \mathrm{C}\right)$ & 27,61 & 0,55 & 28,11 & 0,86 & 0,891 \\
\hline $\operatorname{TR}\left({ }^{\circ} \mathrm{C}\right)$ & 38,28 & 0,06 & 38,55 & 0,12 & 0,059 \\
\hline FR (mrm) & 35,51 & 0,89 & 38,86 & 2,93 & 0,404 \\
\hline
\end{tabular}

Nota: Médias seguidas por letras diferentes diferiram estatisticamente pelo teste de Tukey $(\mathrm{p}<0,05)$.

Tabela 2 - Correlação de Pearson entre parâmetros ambientais, temperatura do ar (TAR), temperatura máxima (TMAX), temperatura mínima (TMIN), amplitude térmica (AT), umidade relativa (UR), índice de temperatura e umidade (ITU), índice de temperatura equivalente (ITE), temperatura retal (TR) e frequência respiratória (FR) de vacas leiteiras mestiças avaliadas no inverno e no verão na mesorregião do Triângulo Mineiro

\begin{tabular}{|c|c|c|c|c|c|c|c|c|}
\hline & $\operatorname{TR}\left({ }^{\circ} \mathrm{C}\right)$ & FR (mrm) & $\mathrm{Ta}\left({ }^{\circ} \mathrm{C}\right)$ & $\operatorname{Tmax}\left({ }^{\circ} \mathrm{C}\right)$ & $\operatorname{Tmin}\left({ }^{\circ} \mathrm{C}\right)$ & At $\left({ }^{\circ} \mathrm{C}\right)$ & UR (\%) & ITU \\
\hline \multirow{2}{*}{ FR } & 0,18 & & & & & & & \\
\hline & $(0,057)$ & & & & & & & \\
\hline \multirow{2}{*}{$\mathrm{Ta}$} & 0,341 & 0,024 & & & & & & \\
\hline & $(0,001)$ & $(0,802)$ & & & & & & \\
\hline \multirow{2}{*}{$\operatorname{Tmax}$} & $-0,186$ & $-2,52$ & 0,159 & & & & & \\
\hline & $(0,05)$ & $(0,007)$ & $(0,094)$ & & & & & \\
\hline \multirow{2}{*}{ Tmin } & 0,014 & 0,212 & $-0,194$ & $-0,027$ & & & & \\
\hline & $(0,886)$ & $(0,025)$ & $(0,041)$ & $(0,778)$ & & & & \\
\hline \multirow{2}{*}{ At } & $-0,110$ & $-0,311$ & 0,246 & 0,552 & $-0,848$ & & & \\
\hline & $(0,249)$ & $(0,001)$ & $(0,009)$ & $(0,001)$ & $(0,001)$ & & & \\
\hline \multirow{2}{*}{ UR } & $-0,235$ & 0,192 & $-0,548$ & $-0,067$ & 0,338 & $-0,317$ & & \\
\hline & $(0,013)$ & $(0,043)$ & $(0,001)$ & $(0,482)$ & $(0,001)$ & $(0,001)$ & & \\
\hline \multirow{2}{*}{ ITU } & 0,301 & 0,119 & 0,922 & 0,157 & $-0,063$ & 0,136 & $-0,183$ & \\
\hline & $(0,001)$ & $(0,212)$ & $(0,001)$ & $(0,098)$ & $(0,509)$ & $(0,153)$ & $(0,054)$ & \\
\hline \multirow{2}{*}{ ITE } & 0,317 & 0,073 & 0,969 & 0,158 & $-0,152$ & 0,211 & $-0,341$ & 0,983 \\
\hline & $(0,001)$ & $(0,446)$ & $(0,001)$ & $(0,097)$ & $(0,001)$ & $(0,026)$ & $(0,001)$ & $(0,001)$ \\
\hline
\end{tabular}

Nota: Correlação de Pearson (valor de p). 
Tabela 3 - Taxa de concepção (\%) de vacas leiteiras mestiças para as estações inverno e verão e para as classes de ITU e de ITE, na mesorregião do Triangulo Mineiro

\begin{tabular}{ccccc}
\hline & Concepção \% & Não Concepção \% & Total \% & P-valor \\
\hline Inverno & 44,64 & 36,61 & 81,25 & 0,83 \\
Verão & 9,82 & 8,83 & 18,75 & \\
ITU $\leqslant 72$ & 27,68 & 23,21 & 50,89 & 0,06 \\
ITU > 72 & 17,86 & 31,25 & 49,11 & \\
ITE $\leqslant 27$ & 14,29 & 19,64 & 33,93 & 0,69 \\
ITE > 27 & 31,25 & 34,82 & 66,07 & \\
\hline
\end{tabular}

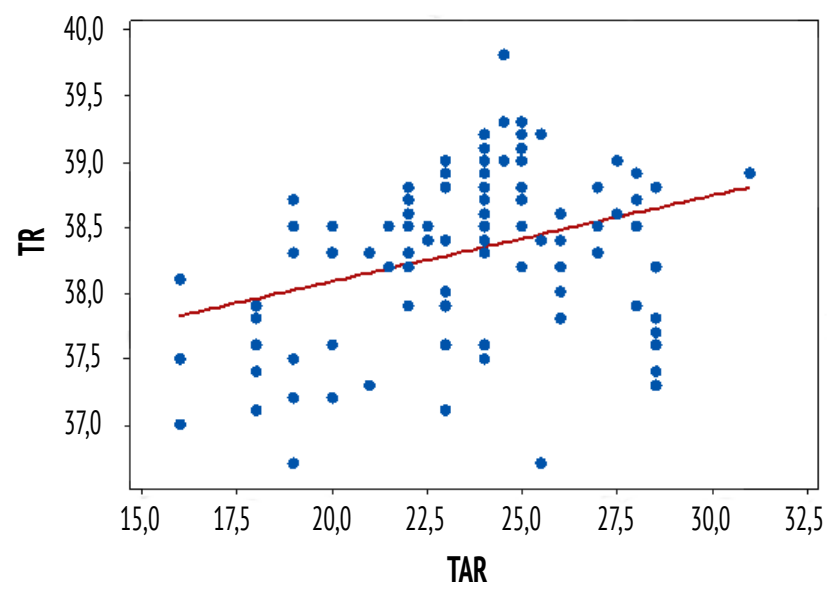

Figura 2 - Regressão linear simples entre temperatura retal (TR) $\left({ }^{\circ} \mathrm{C}\right)$ de vacas leiteiras mestiças e temperatura do ar (TAR) $\left({ }^{\circ} \mathrm{C}\right)$, $\left(\mathrm{TR}=36,79+0,06517^{*} \operatorname{Tar}, \mathrm{R}^{2}=11,6 \%\right)$.

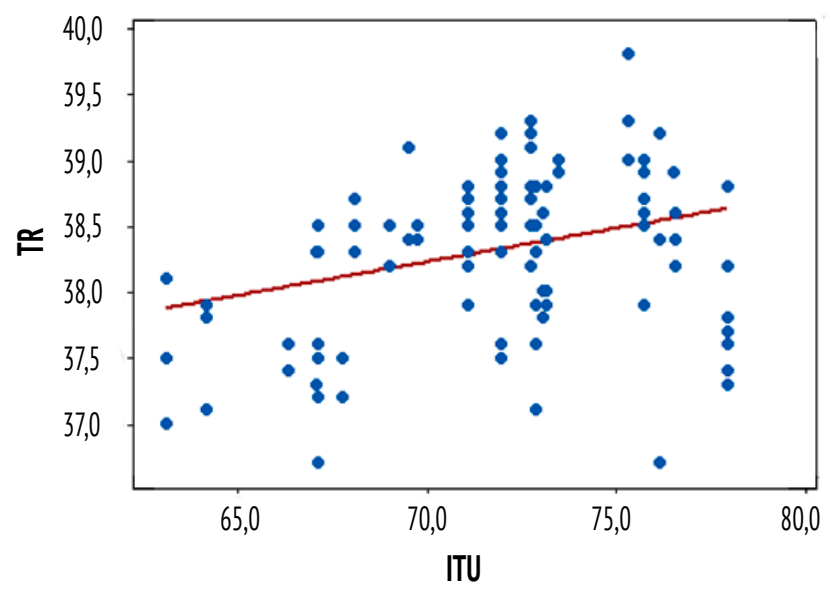

Figura 3 - Regressão linear simples entre temperatura retal (TR) $\left({ }^{\circ} \mathrm{C}\right)$ de vacas leiteiras mestiças e índice de temperatura e umidade (ITU) (TR = 34.66 + 0,05097*ITU, $R^{2}=9,0 \%$ ).

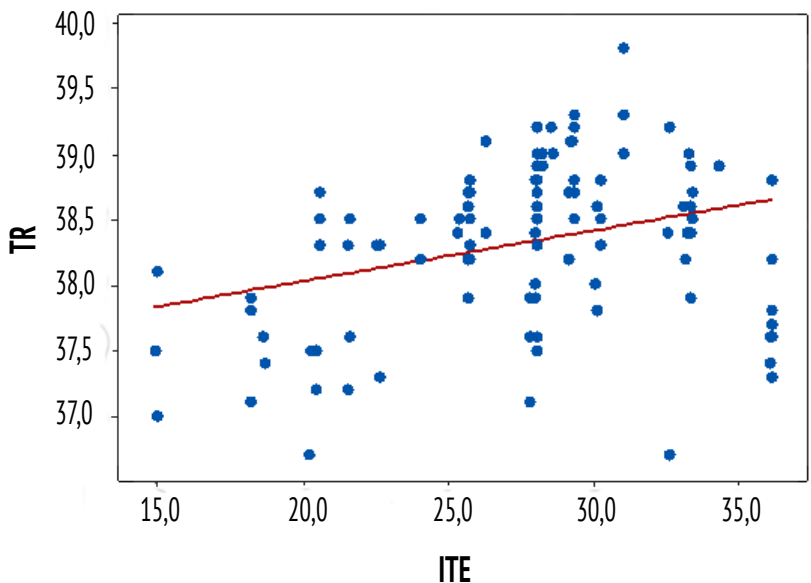

Figura 4 - Regressão linear simples entre temperatura retal (TR) $\left({ }^{\circ} \mathrm{C}\right)$ de vacas leiteiras mestiças e 0 Índice de Temperatura equivalente (ITE) $\left({ }^{\circ} \mathrm{C}\right),\left(\mathrm{TR}=37,26+0,03873^{*} \mathrm{ITE}, \mathrm{R}^{2}=10,1 \%\right)$.

\section{Discussão}

0 ambiente térmico no momento da inseminação artificial nos dois anos de estudo foi semelhante entre as estações inverno e verão, exceto temperatura mínima, amplitude térmica e umidade relativa. Dessa forma, o ambiente térmico encontrou-se dentro da zona de conforto $\left(23^{\circ} \mathrm{C}\right)$. Baêta e Souza (2010) consideram que a temperatura do ar entre $10^{\circ} \mathrm{C}$ e $27{ }^{\circ} \mathrm{C}$ e umidade relativa de 60 a $70 \%$ são condições meteorológicas de conforto térmico para bovinos leiteiros. Em pesquisa realizada pela Embrapa Gado de Leite, verificou-se que temperatura do ar entre $4{ }^{\circ} \mathrm{C}$ e $24{ }^{\circ} \mathrm{C}$ e umidade relativa menor que $75 \%$ seriam o ideal para bovinos leiteiros, podendo ainda restringir essa faixa aos limites entre $7{ }^{\circ} \mathrm{C}$ a $21{ }^{\circ} \mathrm{C}$ em função da umidade relativa do ar e da radiação solar (Antunes et al., 2009).

Por outro lado, ao observar a diferença entre as temperaturas máxima e mínima, 24 horas antes da inseminação no verão, verificou-se que os animais estiveram expostos a uma menor amplitude térmica ao longo do dia em comparação ao inverno, o que prejudica a dissipação do calor. Assim, os animais estiveram mais susceptíveis ao estresse cíclico por calor, onde a menor amplitude térmica favoreceu o maior armazenamento e a menor perda de calor. Aliado a este fator, o verão na mesorregião 
do estudo apresentou elevada umidade relativa do ar (94\%) e valores de temperatura máxima superiores à temperatura crítica, cujo valor é $27{ }^{\circ} \mathrm{C}$. Animais homeotérmicos criados sob temperatura ambiente de conforto estão em equilíbrio térmico entre a produção e a dissipação de calor promovida por mecanismos de perda de calor sensível (condução, convecção e radiação) e pequena parcela por evaporação. Com aumento do desafio térmico, a perda de calor sensível diminui e há elevação da perda de calor por mecanismos evaporativos (cutânea e respiratória), que estão mais condicionados às variações da umidade relativa do ar.

A umidade relativa esteve alta em ambas as estações. Sabe-se que umidade relativa do ar exerce fundamental importância nos processos de trocas de calor com o ambiente, principalmente quando o organismo depende de processos evaporativos para manter a homeotermia. A associação entre temperatura e umidade do ar elevadas com baixa velocidade do vento reduz o desempenho dos animais leiteiros (Nonaka et al., 2012). Os valores médios de ITU, tanto no inverno $(71,70)$ como no verão $(73,05)$, encontraram-se acima do considerado conforto térmico para os bovinos, sendo crítico na classificação de Hahn (1985). Os valores médios de ITE em ambas as estações também estiveram acima de $27{ }^{\circ} \mathrm{C}$ (inverno, $27,61^{\circ} \mathrm{C}$; verão, $28,11^{\circ} \mathrm{C}$ ), porém, Silva et al. (2007) sugerem que para regiões tropicais valores de ITE menores de 30 ainda sejam considerados seguros para vacas leiteiras das raças Holandesa e Jersey.

Consequentemente, a avaliação do conforto térmico dos animais deve ser feita com cautela. Os índices auxiliam nesta avaliação, porém deve-se considerar as variações do ambiente térmico e adaptação dos animais. Azevedo et al. (2005), ao estimarem os valores críticos de ITU para vacas mestiças Holandês-Zebu $(1 / 2,3 / 4$ e 7/8; Holandês/Zebu) com produção média de leite superior a 10 L.dia $^{-1}$, verificaram que para diferentes composições genéticas há alterações no valor crítico do ITU. Sendo assim, para as vacas mestiças Holandês-Zebu, os autores estimaram valores críticos superiores de ITU, iguais a 80 (1/2), 77 (3/4) e $75(7 / 8)$ para variação normal de temperatura retal $\left(38\right.$ a $\left.39{ }^{\circ} \mathrm{C}\right)$.
Aclimatação é a habilidade do animal em se ajustar a um conjunto de condições ambientais, até mesmo a extremos climáticos (McManus et al., 2009). No processo de adaptação, a aclimatação permite ao organismo realizar trabalhos pelo aprimoramento dos mecanismos de dissipação do calor (Moseley, 1997). Dessa forma, a avaliação de parâmetros fisiológicos auxilia no entendimento das respostas termorregulatórias e de adaptação ao calor. A temperatura retal, no momento das coletas, apresentou-se dentro da faixa fisiológica, que é de 38 a $39,5^{\circ} \mathrm{C}$ (Du Preez, 2000), bem como a frequência respiratória que estava dentro do padrão de normalidade (Hahn e Mader, 1997).

Os animais respondem ao estresse de acordo com o tipo de desafio térmico: em eventos agudos, utilizam mecanismos de termorregulação de curto prazo quanto ao comportamento, respostas fisiológicas e funções imunológicas; já nos eventos em longo prazo ocorrem respostas orientadas para o desempenho, sobrevivência, crescimento e reprodução (Nienaber e Hahn, 2007). Demetrio et al. (2007) associaram a temperatura retal com a concepção de vacas leiteiras Holandesas. Os autores concluíram que a elevação da temperatura retal sete dias antes da inseminação artificial ou durante a transferência de embrião provocava efeito negativo no desempenho reprodutivo dos animais.

Badinga et al. (1993) observaram que o estresse térmico iniciado no período da ovulação reduziu o volume e o diâmetro do folículo dominante no $8^{\circ}$ dia do ciclo estral. Hansen e Aréchiga (1999) constataram que ao promover estresse no $11^{\mathrm{o}}$ dia do ciclo estral houve um aumento no número de folículos maiores do que $10 \mathrm{~mm}$, emergência precoce do folículo dominante da $2^{\mathrm{o}}$ onda e, também, tendência de redução na concentração de inibina. 0 estresse causou mais ciclos estrais, caracterizados por três ondas, reduziu a concentração de $17 \beta$-estradiol no sangue e aumentou a duração do ciclo estral (Wilson et al.,1998). Roth (2017) reportou a redução no crescimento folicular e competência oocitária de vacas nas estações mais quentes do ano, com efeitos negativos na performance reprodutiva carreados do verão para o outono.

No presente estudo não houve influência da estação do ano na taxa de concepção, pois as 
inseminações foram realizadas em momentos que contribuiram para o conforto térmico das vacas leiteiras mestiças. Por outro lado, outros estudos comprovaram que a estação do ano interfere na concepção de vacas leiteiras. Pires et al. (2002) observaram que o ambiente térmico do verão afetou a taxa de concepção de vacas Holandesas (verão: 45,7\%; inverno: 71,2\%). No estudo de Souza et al. (2016) foi observada menor taxa de concepção em vacas leiteiras mestiças (Holandês x Gir) nas estações primavera-verão em relação ao outono-inverno $(25,49 \%$ vs. $31.75 \%, p=$ $0,0146)$. Os resultados do presente estudo podem ser explicados pela condição de conforto térmico em que os animais estiveram no momento da inseminação artificial, sendo uma das vantagens da técnica em tempo fixo, pois os animais são inseminados nos períodos mais frescos do dia, amenizando o efeito negativo promovido pelo ambiente térmico (Nebel et al., 1994; Chebel et al., 2004). Pode-se, ainda, considerar a maior tolerância ao calor de animais mestiços, por apresentarem características adaptativas de raças zebuínas.

\section{Conclusão}

Nas condições deste experimento, concluiu-se que o momento em que foram realizadas as inseminações artificiais contribuiu para que os animais estivessem em conforto térmico e, portanto, não foi observado prejuízo na taxa de concepção das vacas leiteiras mestiças. Diante do exposto, reforça-se a necessidade de avaliar e promover o conforto térmico dos animais durante a inseminação artificial para melhoria e manutenção de bons índices reprodutivos. Sugerese, em estudos futuros, mais investigações que relacionem os mecanismos de termorregulação de bovinos leiteiros mestiços com a qualidade oocitária e embrionária em condições tropicais.

\section{Agradecimentos}

À Fundação de Amparo à Pesquisa de Minas Gerais, pelo apoio financeiro para a execução do projeto (FAPEMIG2012-AGR010).

\section{Referências}

Antunes MM, Pazinato PG, Pereira RA, Schneider A, Bianchi I, Corrêa MN. Efeitos do estresse calórico sobre a produção e reprodução do gado leiteiro. Pelotas: Núcleo de Pesquisa, Ensino e Extensão em Pecuária; 2009 [acesso 15 mar 2018]. Disponível em: https://tinyurl. com/ybblxhrk.

Azevedo M, Pires MFA, Saturnino HM, Lana AMQ, Sampaio IBM, Monteiro JBN, et al. Estimativa de níveis críticos superiores do índice de temperatura e umidade para vacas leiteiras 1/2, 3/4 e 7/8 Holandês-Zebu em lactação. R Bras Zootec. 2005;34(6): 2000-8.

Badinga L, Thatcher WW, Diaz T, Drost M, Wolfenson D. Effect of environmental heat stress on follicular development and steroidogenesis in lactating Holstein cows. Theriogenology. 1993;39(4):797-810.

Baêta FC, Souza CF. Ambiência em edificações rurais conforto animal. Viçosa: UFV; 2010. 269 p.

Barbosa CF, Jacomini JO, Diniz EG, Santos RM, Tavares M. Inseminação artificial em tempo fixo e diagnóstico precoce de gestação em vacas leiteiras mestiças. R Bras Zootec. 2011;40(1):79-84.

Beltran MP, Vasconcelos JLM. Conception rate in Holstein cows treated with GnRH or hCG on the fifth day post artificial insemination during summer. Arq Bras Med Vet Zootec. 2008;60(3):580-6.

Bernabucci U, Lacetera N, Baumgard LH, Rhoads RP, Ronchi B, Nardone A. Metabolic and hormonal acclimation to heat stress in domesticated ruminants. Animal. 2010;4(7):1167-83.

Brown-Brandl TM, Nienaber JA, Eigenberg RA, Hahn GL, Freetly H. Thermoregulatory responses of feeder cattle. J Therm Biol. 2003;28(2):149-57.

Chang LB, Chou CJ, Shiu JS, Tu PA, Gao SX, Peng SY, et al. Artificial insemination of Holstein heifers with sex-sorted semen during the hot season in a subtropical region. Trop Anim Health Prod. 2017;49(6):1157-62.

Chebel RC, Santos JE, Reynolds JP, Cerri RL, Juchem SO, 
Overton M. Factors affecting conception rate after artificial insemination and pregnancy loss in lactating dairy cows. Anim Reprod Sci. 2004;84(3-4):239-55.

De Rensis F, Scaramuzzi RJ. Heat stress and seasonal effects on reproduction in the dairy cow - a review. Theriogenology. 2003;60(6):1139-51.

Demetrio DGB, Santos RM, Demetrio CGB, Vasconcelos JLM. Factors affecting conception rates following artificial insemination or embryo transfer in lactating Holstein cows. J Dairy Sci. 2007;90(11):5073-82.

Du Preez JH. Parameters for the determination and evaluation of heat stress in dairy cattle in South Africa. Onderstepoort J Vet Res. 2000;67(4):263-71.

Finch VA. Body temperature in beef cattle: its control and relevance to production in the tropics. J Anim Sci. 1986;62(2):531-42.

Golher DM, Thirumurugan P, Patel BHM, Upadhyay VK, Sahu S, Gaur GK, et al. Effect of drinking water temperature on physiological variables of crossbred dairy cattle at high altitude temperate region of Himalayas. Vet World. 2015;8(10):1210-4.

Habeeb AAM, Gad AE, El-Tarabany AA, Atta MAA. Negative effects of heat stress on growth and milk production of farm animals. J Anim Husb Dairy Sci. 2018;2(1):1-12.

Hahn GL. Management and housing of farm animals in hot environments. In: Yousef MK (E.). Stress Physiology in Livestock, vol 2. Boca Raton: CRC Press; 1985. p. 151-74.

Hahn G, Mader T. Heat waves in relation of thermoregulation, feeding behavior, and mortality of feedlot cattle. 5th International Symposium - Livestock Environment; 29-31 mai 1997; Bloomington, Minnesota. St. Joseph, MI: ASAE; 1997. p. 563-71.

Hansen PJ, Aréchiga CF. Strategies for managing reproduction in the heat-stressed dairy cow. J Anim Sci. 1999;77(Supl 2):36-50.

Kamal R, Dutt T, Patel M, Dey A, Bharti PK, Chandran PC. Heat stress and effect of shade materials on hormonal and behavior response of dairy cattle: a review. Trop Anim Health Prod. 2018;50(4):701-6.

McManus C, Prescott E, Paludo GR, Bianchinia E, Louvandinia $\mathrm{H}$, Mariante AS. Heat tolerance in naturalized Brazilian cattle breeds. Livest Sci. 2009;120(3):256-64.

Moseley PL. Heat shock proteins and heat adaptation of the whole organism. J Appl Physiol (1985). 1997;83(5):1413-7.

Nebel RL, Walker WL, McGilliard ML, Allen CH, Heckman GS. Timing of artificial insemination of dairy cows: fixed time once daily versus morning and afternoon. J Dairy Sci. 1994;77(10): 3185-91.

Nienaber JA, Hahn GL. Livestock production system management responses to thermal challenges. Int J Biometeorol. 2007;52(2):149-57.

Nonaka I, Takusari N, Higuchi K, Enishi O, Kurihara M. Effects of a hot and humid environment on the performance of Holstein heifers. Jpn Agric Res Q. 2012;46(3):221-6.

Pires MFA, Ferreira AM, Saturnino HM, Teodoro RL. Taxa de gestação em fêmeas da raça Holandesa confinadas em free stall, no verão e inverno. Arq Bras Med Vet Zootec. 2002;54(1):57-63.

Roth Z. Effect of heat stress on reproduction in dairy cows: Insights into the cellular and molecular responses of the oocyte. Annu Rev Anim Biosci. 2017;5:151-70.

Silanikove N. Effects of heat stress on the welfare of extensively managed domestic ruminants. Liv Prod Sci. 2000;67(1-2):1-18.

Silva RG. Introdução à bioclimatologia animal. São Paulo: Nobel; 2000. 286 p.

Silva RG, Morais DAEF, Guilhermino MM. Evaluation of thermal stress indexes for dairy cows in tropical regions. R Bras Zootec. 2007;36(4):1192-8.

Smith AC, Coombs CO, Bewley JM. Management practices employed by the top dairy farms in Kentucky. Prof Anim Sci. 2013;29(4):367-71. 
Sørensen MK, Norberg E, Pedersen J, Christensen LG. Invited Review: crossbreeding in dairy cattle: a Danish perspective. J Dairy Sci. 2008;91(11):4116-28.

Souza FR, Campos CC, Silva NAM, Santos RM. Influence of seasonality, timing of insemination and rectal temperature on conception rate of crossbred dairy cows. Semina Cienc Agrar. 2016;37(1):155-62.

Soydan E, Ocak N, Onder H. Conception of Jersey cattle in Turkey. Trop Anim Health Prod. 2009;41(4):623-8.

Van laer E, Moons CPH, Sonck B, Tuyttens FAM. Importance of outdoor shelter for cattle in temperate climates. Livest Sci. 2014;159:87-101.

Wilson SJ, Kirby CJ, Koenigsfeld AT, Keisler DH, Lucy MC. Effects of controlled heat stress on ovarian function of dairy cattle. 2. Heifers. J Dairy Sci. 1998;81(8): 2132-8. 